eyes a heavy blow had been inflicted during life, as also on the upper lip, in proximity with which parts considerable extravasation of blood existed. I pointed out these facts to the constable who was present, and directed him to inform the coroner of the same. On the following evening an inquest was held, when (the name, \&c., of the deceased having been identified) the widow yave evidence that he left his house on Sunday morning, March 25th, about half-past seven o'clock, saying he should return in a short time to breakfast; that he appeared to be in his usual health, and that she had not seen nor heard of him since that time until she saw him dead on the morning of the day then present (the $12 \mathrm{th}$ inst.); that he was not in the habit of spending a night out of his own house.

At the inquest, the constable was asked if there were any marks of violence on deceased, and he replied that there were only a few scratches on the face, which might, it was intimated, have occurred from the rolling of the body in the water This closed the evidence, and after a consultation for about half an hour, the jury returned a verdict of "Suicide under temporary insanity." No medical evidence was called, or there might have been a different verdict. Nor can we wonder that a coroner should so often refrain from calling in such evidence, since, as the present coroner told me on a former occasion, the fee was sometimes disallowed, and that he had had to pay it in some cases out of his own pocket. Thus, as the law and practice now stand, any man may be knocked down at night -in this neighbourhood at least--have his pockets rifled, and then be thrown into one of our numerous ditches, or into one of the streams of the Wandje, and at the inquest no medical testimony - the only really valuable testimony in such caseswould be adduced.

I trust, Sir, that you, to whom the public in general and the medical body in particular are so much indebted for salutary reforms, will employ your able pen in exposing an evil so much to be deprecated.

I remain, Sir, yours faithfully,

* * The extravasation of blood over the eyes would certainly indicate that the man had been the subject of considerable external violence. We cannot understand why the coroner omitted to order a post.mortem examination, and to call $\mathrm{Mr}$. Davie as a witness. The fees of medical witnesses at inquests are paid under the authority of a special Act of Parliament, and the Quarter Sessions has no power to disallow them. We refe to the Statute 6 and 7 William IV., cap. 89.-ED. L.

\section{THE UNIVERSITY OF LONDON AND DR. QUAIN.}

To thie Editor of The LANCET.

SJR, - You will oblige a very old subseriber if you will afford a corner in the next number of THE LANCET for the note here. with enclosed:-

" Carlow, Ireland, April, 1860.

"SIR, - T had the honour to receive your circular of the 10 th instant, advocating the claims of Dr. Quain to a seat in the Senate of our University. I have the greatest respect for Dr. Quain. The high position he has attained as a physician reflects credit upon the University. I should be most happy to support his nomination to the vacant seat if $I$ had retained a vote in Convocation.

"But there is one part of your circular to which I must object. You state that Dr. Quain' obtained the first medical scholarship awarded in the University.' By referring to the Calendar, you will find that there were two medical scholar. ships awarded at the examination for honours held in 1840 . The scholarship in Physiology and Comparative Anatomy was conferred on Dr. Quain, and the scholarship in Medicine on the undersigned. There was no priority of date as regarded these two scholarships. I am sure it is only necessary to draw your attention to the error in order to have it corrected.

$$
\text { "I am, Sir, your obedient servant, }
$$$$
\text { "Thomas O'Meara, M.B. }
$$$$
\text { "Ex-Universitv Medical Scholar, London, }
$$

"Visiting Physician to the Carlow Distriet Lunatie Asylum. " To Henry Thompson, Esq., M.B., Secretary."

* We congratulate the profession on the probable election of Dr. Quain to a seat in the Senate of the University of London. The prestige of the London University is mainly due to the reputation of its medical graduates. The number, the high character, and considerable attainments of the medical graduates of the University have elevated their faculty to the highest honours of the profession. The University was intended to provide for those who sought a high academical training at less cost and inconvenience than an $\mathrm{Ox}$ ford or Cambridge degree entails upon candidates. It has attained this object more perfectly in respect to medical students than to students of the other faculties, because the great hospitals of London afford opportunities of clinical teaching which do not exist at either of the more ancient seats of learn. ing. Hence the great growth and high character of the medical department of the University. In the Senate, however, the representatives of the medical element are in a decided minority; and while greatly contributing to the honour and importance of the Alma Mater, the graduates in medicine have not yet been admitted to that full share in its counsels which they may fairly and usefully claim. We strongly advise the graduates in medicine to exert their utmost efforts to obtain an additional medical representative in the Senate. Dr. Quain has all the claims for this honour which any man can have. His high professional position, his amiable personal character, his liberal, moderate views, and his thorough identification with every movement which has tended to advance the interests of the University, combine to recommend him for the position. Unanimity is of great avail in such a cause; and we hope to see a cordial and concurrent effort made on this occasion which will prevent the claims of our profession from being ignored or defeated.-ED. L.

\section{THE SUMMER STENCH OF THE THAMES.}

(LETTER FROM DR. J. MEGRIGOR CROFT.)

\section{To the Editor of THE LANCRT.}

SIR,--An article in your journal of the 3 lst ult. has recalled to memory my voluminous correspondence, last summer, with the chairman of the Metropolitan Board of Works, on a proposition of mine for removing the fearful smell of the river during the dog days. The difficulty I had in obtaining from that honourable Board "a crooked answer to a cross-question" enabled them to enter the winter period, thinking, no doubt, to congeal my crotchets. Not so. With the bull-dog disposition of the Anglo-Saxon race, I wish to lay hold of the Board again: not hitting at them direct-that I found no nse; but a "side dig" with a powerful LANCET may have effect.

Many, no doubt, who travel the slimy deep of the great sewer, for pleasure or business, will pause ere they do so this summer. Penny steam-boat passengers will swear and hold their noses. Captains, engineers, stokers, and call-boys will say a prayer for some, wishing those who are poisoning them were "chucked" into the river. Ask any of the amphibians whom they allude to: "Can't tell." But my humble opinion is, that if the Thames continues in as bud odour as last season, the Metropolitan Board of Works, who, you well remark, have never been otherwise than under the same title, will come in for a large share of the pie.

Now, Sir, I took the trouble, last year, of "driving" up and down the great cesspool in penny steam-yachts for the osten. sible pleasure of discovering when and where I could bring my olfactory nerves in contact with the most abominable emanations of sulphuretted hydrogen; and, if my experience can be borne out by others, I came to a very satisfactory conclusion,namely, that if in the body of the river there was a "stink," nowhere did I derive more perfume than at the call-barge stations of the steamers. Various were the questions I put to the commanders and crews of many boats. All were manimous, that if I wanted "real poison" I should just hang on to one or any of their stations about midday in hot weather, when their boats were backing and filling, going ahead and going astarn, stirring up the pudding in real earnest. "Well," says I, to one of the commanders, after testing the proposition, "you are right. I guess I could rectify it rather." "How ?" was the interrogation. "Can you "' says a greasy engineer, popping his head up the stokehole, and taking a survey of my corpus: " if you can, the Lord Mayor ought to give you the freedom of the city in a gold box." I explained my proposition in plain words." "Well," said they. "it seems easy too." "I understand," says the intelligent but smoke-begrimed engineer. "I 
The Laycet,] STRICTURE OF THE GESOPHAGUS.-NAVAL SURGEONS ON HALF-PAY. [APRIL $28,1860$.

heartily wish that 'ere Board of Works, or whatever they call themselves, would help us out with it."

Now, Sir, the idea is this. The large number of river steamers plying between Battersea and London-bridge in summer are constantly stirring up the filth that escapes deodorization in the sewers, wore especially that lying along the banks and barge-stations. The heat of the sun acting on the liquid sewage, increases in an enormous degree the fearful stench. As the steamers cause this, make them consume it, as they do their own smoke. My plan is simply to fit a flat tank on the after-part of the deck, near the steering-wheel, capable of holding about two hogsheads of deodorizing fluid; a pipe descending down the rudder-case would allow the fluid to pass away, regulated by a stop-cock. This would mix efficiently with the sewage stirred up by the paddles, and where the odour was strongest there would the remedy be applied.

Professor Miller acknowledged to me, last summer, that he had no doubt the process would be successful. It is simple, practical, and inexpensive. If half a gallon of Dale's muriate of iron will deodorize 7500 gallons of sewage perfectly, think what may he done by the river steamers in connexion with the deodorization in the sewers. If, Sir, the hint is worthy a place in your columns, give room to this "pleonastic epistle," and oblige your obedient servant,

J. M'Grigor Croft, M.D., M.R.C.P. Lond., Late Staff-Surgeon to $\mathrm{H}$ M $\mathrm{E}$.

Maudarin Villa, Abbey-road, St. John's-wood, April, 1860.

\section{STRICTURE OF THE ESOPHAGUS.}

(LETTER FROM MR. MACILWATN.)

To the Editor of THE LANCET.

Srr,-On almost every occasion on which Strictures of the CEsophagus have been the subject of conversation, I have experienced great difficulty in persuading my surgical brethren that there is much to be done in these cases; whereas, as $I$ have always said, there are no cases in which, if treated with the care necessary, both constitutionally as well as locally, we obtain more gratifying or triumphant issues. I am seldom without a case in illustration of the foregoing assertion. Strictures of the cesophagus are further of creat interest, because in exacting a far more severe or rigid attention to the principles on which these diseases should be treated than is usually given, they bring up in greater relief those which should govern our management of similar affections in other cants of the body.

I have lately received the account of the death of a patient, whose case I published in 1834, and who died only ten days since, at the age of eighty-seven. Her son, from whom $I$ received the narrative, states as follows (the underscoring being his own):-_ I am happy to say, that my dear mother expe. rienced no kind of pain or suffering, and died of no disease. She left this world without a struggle or a groan-a truly happy, peaceful end, quite in character with the Christian life she had lived for eighty-seven years. She did not experience any inconvenience from her swallow, nor require the use of the instrument for the last seven or eight years," \&c.

The case, when I published it, twenty six years ago, was that of a lady, said to have been about fifty years old (though she must, you see, have been nearer sixty). She was a nervous subject, and dated her first difficulty as far back as twenty years. Her treatment consisted of rigid attention to her general health, and the very careful use of a bougie, preceded by three applications of nitrate of silver in solution. Her surgeon in the country-the late Mr. Dyer, of Ringwood-was directed to continue attention to those points on which her general health appeared to depend, and now and then in the course of the year, if anything suggested its propriety, to pass an elastic gum bougie.

As I have already occupied more space than I had hoped to have done, I will only add, that the experience I have had of these cases has convinced me that their imputed obstinacy has resulted (malignant disease apart) from too much reliance having been placed on the local and manipulatory measures, and too little on the constitutional treatment, the success of which is necessary to the efficient and safe progress of the manipulatory proceedings. I am, Sir, your obedient servant,

Albany Court-yard, April, $1860 . \quad$ Geo. Macrlwais, F.R.C.S.

P.S. - The patient resided at a distance in the country, and $I$ only heard of the death the day before the interment, so that there was no opportunity afforded for any examination of the part. - G. M.

\section{NAVAL SURGEONS ON HALF.PAY.} To the Editor of THE LANCET.

Sir,-We beg to enclose you a copy of a requisition presented by a deputation from the medical practitioners of this borough to Sir John Liddell, M.D., Director-General of the Navy.

We are, Sir, yours obediently,

Portsmouth, April, 1860.

$\left.\begin{array}{l}\text { F. J. Burgess, } \\ \text { Fred. Page, }\end{array}\right\}$ Hon. Secs.

"We, the undersigned qualified private practitioners, resident in Portsmouth, Portsea, Southsea, Landport, and Gos. port, beg most respectfully to call the attention of the DirectorGeneral of the Naval Medical Department to the very great injustice we feel we have long been placed under, from the fact of there being young and able naval medical officers settled and practising in this locality, their half-pay placing them in an unfair position as regards ourselves, enabling them to live in a style and dash that generally ensure success. And we further feel ourselves aggrieved, inasmuch as we are called upon largely to contribute towards their support by the present Income-tax, taxing in a serious manner the pockets of our always precarious incomes. We need not state the labour and fatigue attending private compared with official practice; and we now most respectfully solicit that it may please the Director. General to take this representation into his serious consideration, and to relieve us from a grievance which we feel sure has only to be represented to be remedied.

"Frederick Josiah Burgess, Ext. Lic. R. C.P. Lond. \& F.R.C.S. Lond., Hampshire-terrace, Southsea.

Jas. GredthaM, M.R.C.S. Edin., \& L.A.S., King-street, Portsea.

A LLen A. Duxk, M.D., Prince George-street, Portsea.

StePheN R. Niblett, Lic. R.C.P. Edin. \& L.A.S., Daniel-street, Portsea.

Geo. F. Bloxsome, M.R.C.S. \& L.A.S., Brunswickterrace, Southsea.

H. Bloxam, M.R.C.S. \& L.A.S., Parade, Portsmouth. FRED. PAGE, M.D., H.R.C.S., \& L.A.S., Landport.

John O'Sulltvan, L. R. C.P. Lond.

JA Mres Dickson, L. R. C.S. Edin.

G. J. Scale, M.R.C.S. \& L.A.S., Land port, Portsmouth. John Butcher, M. T.C.S. \& L.A.S., Gosport.

John Robert Kealy, M.R.C.S. \& L.A.S., Gosport. WM. JoHN RUNDLE, M.D., Ext. Lic. R.C.P. Lond。 \& M.R.C.S., Gosport.

Henry Slight, M.R. C.S., Highland Cottage.

Julia.y Sligiti, M.R.C.S., Portsmouth.

Gicilard Bachelor, Surgeon, Southsea. "Portsmouth, April 18th, 2860."

\section{COMPLICATED INJURIES ABOUT THE SHOULDER.JOINT.}

To the Editor of THE LANCeT.

SIR,-I beg to make a few remarks on the following paragraph in your impression of April 14th, p. 369 :-

"A case of more than usual interest occurred to me lately in the person of a man, aged sixty, in Abernethy ward, who had sustained an injury to the shoulder three weeks prior to his admission. The head of the humerus was obviously thrown from its socket, and the flattening of the shoulder was unusually great. The deltoid was tight, and the elbow was drawn from the side. The arm was lengthened by one inch. The head of the bone rotated with the shaft; the coracoid process was unbroken, but there was distinct crepitus on moving the arm. The man was very positive in his assurance that the injury was caused by a direct fall on the shoulder. I made an attempt to reduce the dislocation, under chloroform, by the aid of pulleys. I brought the bone towards its natural relation to the acromion process, by extension downwards, with a padded fulcrum in the axilla. The natural rotundity of the shoulder was restored during the extension, but on its remission it dis. appeared. On the second day following, I repeated the attempt, more critically, persevering in the extension for nearly half an hour, but with no better success. While under extension the head of the bone became prominent, but returned to its abnor. mal position on remitting the extending force."

Now, Sir, there is a form of injury of the shoulder commonly recognised by surgical writers, the distinctive characters of which the younger branches of our profession, especially those 